\title{
Effects of amantadine on circulating neurotransmitters in healthy subjects
}

\author{
Fuad Lechin • Bertha van der Dijs • \\ Betty Pardey-Maldonado · Jairo E. Rivera • \\ Scarlet Baez $\cdot$ Marcel E. Lechin
}

Received: 20 September 2009/ Accepted: 10 January 2010/Published online: 4 February 2010

(C) The Author(s) 2010. This article is published with open access at Springerlink.com

\begin{abstract}
Considering that glutamatergic axons innervate the $\mathrm{C} 1(\mathrm{Ad})$ medullary nuclei, which are responsible for the excitation of the peripheral adrenal glands, we decided to investigate catecholamines (noradrenaline, adrenaline and dopamine) plus indolamines (plasma serotonin and platelet serotonin) at the blood level, before and after a small oral dose of amantadine, a selective NMDA antagonist. We found that the drug provoked a selective enhancement of noradrenaline plus a minimization of adrenaline, dopamine, plasma serotonin and platelet serotonin circulating levels. Significant enhancement of diastolic blood pressure plus reduction of systolic blood pressure and heart rate paralleled the circulating parameter changes. The above findings allow us to postulate that the drug was able to enhance the peripheral neural sympathetic activity. Minimization of both adrenal
\end{abstract}

F. Lechin · B. van der Dijs · B. Pardey-Maldonado .

J. E. Rivera

Section of Psychopharmacology, Instituto de Medicina

Experimental, Universidad Central de Venezuela,

Caracas, Venezuela

F. Lechin · B. van der Dijs · S. Baez

Section of Clinical Neurochemistry, Instituto de Medicina

Experimental, Universidad Central de Venezuela,

Caracas, Venezuela

M. E. Lechin

A\&M University, College Station, TX, USA

F. Lechin $(\bowtie)$

Sección de Neuroinmunofarmacología,

Departamento de Ciencias Fisiológicas, Facultad de Medicina, Instituto de Medicina Experimental, Universidad Central de Venezuela, Apartado 80.983, Caracas 1080, Venezuela

e-mail: flechin@telcel.net.ve sympathetic and parasympathetic activities was also registered after the amantadine challenge. The above findings supported the postulation that this drug should be a powerful therapeutic tool for treating diseases affected by adrenal sympathetic hyperactivity.

Keywords Adrenal sympathetic activity · Neural sympathetic activity $\cdot$ Amantadine $\cdot$ Rostral ventrolateral medullary $\mathrm{C} 1(\mathrm{Ad})$ nuclei $\cdot$ A5(NA) pontomedullary nucleus - NMDA glutamatergic antagonist .

Neural sympathetic activity - Adrenal sympathetic activity - Serotonin · Adrenaline · Noradrenaline . Catecholamines

\section{Introduction}

Adrenal glands secrete adrenaline (Ad) $(80 \%)+$ noradrenaline (NA) and dopamine (DA) (20\%), approximately. Sympathetic nerves release NA (80-90\%) plus DA. Both branches of the peripheral sympathetic activity may act in association or dissociation (Young et al. 1984), in accordance with the physiological and/or pathophysiological circumstances. At the central nervous system level, the C1(Ad) rostral ventral lateral (RVL) medullary nuclei and the A5(NA) pontomedullary nucleus are responsible for these two branches of the peripheral autonomic nervous system (ANS), respectively (Bazil and Gordon 1993; Byrum and Guyenet 1987; Guyenet 1984; Li et al. 1992; Loewy and Haxhiu 1993; Morrison et al. 1991; Strack et al. 1989; Woodruff et al. 1986). Both CNS structures interchange inhibitory axons. Adrenaline released from C1-axons inhibits A5(NA) neurons by acting at alpha-2 post-synaptic receptors, whereas NA released from A5(NA) axons inhibits the adrenergic nuclei by acting at alpha-2 
inhibitory receptors located at these latter ( $\mathrm{Li}$ et al. 1992; Strack et al. 1989; Woodruff et al. 1986).

Amantadine, a glutamate (NMDA) antagonist is considered as an anti-Parkinson agent because it might attenuate the glutamatergic + acetylcholinergic over the dopaminergic predominance at the striatal level (Bibbiani et al. 2005). However, considering that glutamate axons innervate and excite the RVL medullary nuclei, responsible for the adrenal sympathetic activity, by acting at NMDA receptors (Bazil and Gordon 1993; Hand et al. 1997; Morrison et al. 1991), we decided to asses circulating neurotransmitters before and after an oral dose of the drug. With respect to this, we should inform that we have measured those parameters in some 20,000 normal and diseased subjects. Noradrenaline (NA), adrenaline (Ad), dopamine (DA), platelet serotonin (p5-HT), plasma serotonin (f5-HT) and plasma tryptophan have been assessed during supine-resting state and after many types of physiological and pharmacological challenges. The above parameters have been investigated also in a great deal of psychiatric and somatic diseases during both relapses and remission periods (Lechin et al. 1996; Lechin and van der Dijs 2006a, b). Finally, although we have investigated the effects of amantadine on circulating neurotransmitters throughout the oral glucose challenge (Lechin et al. 2009), we decided to assess the above parameters without the sugar administration.

\section{Materials and methods}

\section{Experimental design}

Levels of plasma noradrenaline (NA), adrenaline (Ad), dopamine (DA), free-serotonin (f5-HT), tryptophan, and platelet serotonin (p5-HT) as well as systolic blood pressure, diastolic blood pressure, and heart rate were measured before $(0 \mathrm{~min})$ and after $(60,90$ and $120 \mathrm{~min})$ the oral administration of $100 \mathrm{mg}$ of amantadine in 35 healthy volunteers. Platelet aggregation was measured before and after $120 \mathrm{~min}$ of the drug administration. We performed similar measurements 2 weeks before, in the same volunteers after administration of placebo. The group of volunteers comprised 19 men and 16 women, whose ages ranged from 26 to 62 years (mean $\pm \mathrm{SE}=43.5 \pm 4.8$ ). Informed consent was obtained in writing from all volunteers, and the procedure was approved by the ethical committee of FUNDAIME. All volunteers were within $10 \%$ of ideal body weight, none had any physical or psychiatric illness. Exclusion criteria included pregnancy, lactation, smoking, and alcohol abuse. Volunteers were recumbent during all procedures. A heparinized venous catheter was inserted into a forearm vein at least 30 min before beginning the test. We used cold, plastic syringes to collect blood samples at the times specified above. Amantadine $(100 \mathrm{mg})$ was administered orally after the first blood sample $(0 \mathrm{~min})$ was obtained. Blood samples were obtained for measuring plasma neurotransmitters and platelet aggregation. Blood for measuring plasma neurotransmitters was transferred to plastic tubes, each containing $1 \mathrm{ml}$ of an anti-oxidant solution $(20 \mathrm{mg}$ of EDTA plus $10 \mathrm{mg}$ of sodium metabisulphite per $\mathrm{ml}$ ). The tubes were carefully inverted several times and placed on ice until centrifugation. To obtain platelet-rich plasma (PRP), the tubes were centrifuged at $600 \mathrm{rpm}$ at $4^{\circ} \mathrm{C}$ for $15 \mathrm{~min}$. Two milliliters of PRP was stored at $-70^{\circ} \mathrm{C}$ until needed for determination of p5-HT levels. The remaining blood was centrifuged again at 7,000 rpm, and two aliquots of the supernatant, which was platelet-poor plasma (PPP), were stored at $-70^{\circ} \mathrm{C}$ until needed for determination of catecholamines and f5-HT levels. Blood samples for platelet aggregation were processed immediately. A physician in constant attendance noted any symptoms reported by the subjects and monitored heart rate and blood pressure.

Analytical assays

\section{Neurochemistry}

Plasma catecholamine and serotonin samples were measured in duplicate, and all determinations were made at the same time. We used reverse-phase, ion-pair high performance liquid chromatography with electrochemical detection for the detection of monoamines. Optimization of chromatographic conditions and attainment of adequate quantification parameters allowed us to maximize sensitivity and reproducibility (Lechin et al. 1998).

\section{Reagents and standards}

Noradrenaline, adrenaline, dopamine, serotonin creatinine sulphate, dihydroxybenzylamine, sodium octyl sulphate, dibutylamine, acid-washed aluminium oxide, $\mathrm{Na}_{2} \mathrm{HPO}_{4}$, citric acid and EDTA were purchased from Sigma-Aldrich (St. Louis, MO, USA). Microfilters were purchased from Whatman GmbH (Germany) through Merck S.A (Caracas, Venezuela). Acetonitrile and 2-propanol were obtained from Merck, S.A. (Caracas, Venezuela). Glass-distilled water was de-ionized and filtered through a Milli-Q reagent grade water system (Millipore, Bedford, MA, USA). Solvents were filtered through a $0.2-\mu \mathrm{m}$ Millipore filter and were vacuum de-aerated. Standard solutions $(1 \mathrm{mmol} / \mathrm{l})$ were prepared in $0.1 \mathrm{~mol} / \mathrm{l}$ perchloric acid and diluted to the desired concentration. 


\section{Equipment}

Liquid chromatography was performed using Waters 515 HPLC pump (Waters Corporation, Milford, MA, USA) equipped with a Rheodyne valve injector $7125 \mathrm{i}$, which was fitted with a $50 \mu$ l sample loop (Rheodyne; Berodine, Berkeley, CA, USA). A $15 \mathrm{~cm} \times 4.6 \mathrm{~mm}$ inner diameter Discovery C18 column packed with octadecylsilane $5 \mu \mathrm{m}$ particles was preceded by a column prefilter of $2 \mu \mathrm{m}$ porosity, both from Supelco/Sigma-Aldrich (SigmaAldrich, St. Louis, MO, USA). The detection system was a Waters 460 Electrochemical Detector (Waters Corporation, Milford, MA, USA). The potential of the working electrode (glassy carbon) was set at $+0.61 \mathrm{~V}$ versus the $\mathrm{Ag}-\mathrm{AgCl}$ reference electrode for the detection of catecholamines and $0.70 \mathrm{~V}$ versus the $\mathrm{Ag}-\mathrm{AgCl}$ for the detection of indolamines. The chromatograms were registered and quantified with the Empower software from Waters Corp. The results were corrected for the volume of EDTA added.

\section{Catecholamines assay}

The assay was performed by extraction of the catecholamines onto $20 \mathrm{mg}$ of alumina followed by their elution with $200 \mu \mathrm{l}$ of $1.0 \mathrm{~mol} / 1 \mathrm{HClO}_{4}$ using Regenerated Cellulose microfilters $0.2 \mu \mathrm{m}$ pore size (Whatman $\mathrm{GmbH}$ ). The instrument was calibrated with standard plasma: after incubation with acid-washed aluminium oxide, a plasma pool of free catecholamines was processed similar to plasma samples, but $20 \mu \mathrm{l}$ of a standard solution of noradrenaline, adrenaline and dopamine $(50,25$ and $25 \mathrm{ng} / \mathrm{ml}$, respectively) was added to the plasma pool. Both the standard plasma and the sample plasma were supplemented with $20 \mu \mathrm{l}$ of internal standard $(100 \mathrm{ng} / \mathrm{ml}$ of dihydroxybenzylamine). The mobile phase was $\mathrm{KH}_{2} \mathrm{PO}_{4} 6.8045$ $\mathrm{g} / \mathrm{l}$, EDTA $0.100 \mathrm{~g} / \mathrm{l}$ and di- $N$-butylamine $100 \mu \mathrm{l} / \mathrm{l}$. Sodium octyl sulphate was added as ion-pair agent in a concentration of $0.6125 \mathrm{~g} / \mathrm{l}$ with the $\mathrm{pH}$ adjusted to 5.6. The sensitivity of this method for noradrenaline, adrenaline and dopamine was $6.4,5.8$ and $2.0 \mathrm{pg} / \mathrm{ml}$, respectively. The intra-assay coefficients of variation were $2.8,4.0$ and $4.0 \%$, respectively. The inter-assay coefficients of variation were $6.7,4.5$ and $4.3 \%$, respectively.

\section{Serotonin assay}

After sonication of PRP to disrupt the platelets (Ultrasonic Liquid Processor, model 385; Heat Systems Ultrasonics Inc., Farmingdale, NY, USA), both platelet-rich and platelet-poor plasma were processed in the same way: $200 \mu \mathrm{l}$ of $3.4 \mathrm{~mol} / \mathrm{l}$ perchloric acid and $50 \mu \mathrm{l}$ of 5-hydroxytryptophan solution $(114.5 \mu \mathrm{g} / \mathrm{ml})$ as internal standard were added to $1 \mathrm{ml}$ of plasma, vortexed and centrifuged at
$10,000 \mathrm{rpm}$ for $15 \mathrm{~min}$ at $4^{\circ} \mathrm{C}$. The supernatant was filtered through a $0.22 \mu \mathrm{m}$ membrane (Millipore) and $10 \mu \mathrm{l}$ was injected into the column. Calibration runs were generated by spiking blank platelet-poor plasma with $50 \mu \mathrm{l}$ of a solution containing $5-\mathrm{HT} \quad(10 \mu \mathrm{g} / \mathrm{ml})$ and $50 \mu \mathrm{l}$ of 5-hydroxy-tryptophan $(114.5 \mu \mathrm{g} / \mathrm{ml})$. This standard plasma was processed in the same manner as the samples. The mobile phase was citric acid $3.8424 \mathrm{~g} / 1$, sodium acetate $4.1015 \mathrm{~g} / \mathrm{l}$, EDTA $0.100 \mathrm{~g} / \mathrm{l}$, di- $N$-butylamine $100 \mu \mathrm{l} / \mathrm{l}$ and $30 \mathrm{ml} / 1$ of 2-propanol. Sodium octyl sulphate was added as ion-pair agent in a concentration of $4.25 \mathrm{mg} / \mathrm{l}$ with a $\mathrm{pH}$ of 5.0. The sensitivity of the method for serotonin was $0.1 \mathrm{ng} /$ $\mathrm{ml}$. The intra-assay coefficients of variation for $\mathrm{p} 5-\mathrm{HT}$ and f5-HT were 6.2 and $8.7 \%$, respectively.

\section{Platelet aggregation}

Blood was collected with citrate-phosphate dextrose (1:9 $\mathrm{v} / \mathrm{v})$ as the anticoagulant. Blood was subsequently centrifuged at $120 \mathrm{~g}$ for $10 \mathrm{~min}$ to prepare PRP. Aggregation studies were carried out according to Born's (1962) method, and aggregation was induced by ADP and collagen at final concentrations of $4 \mu \mathrm{mol} / \mathrm{l}$ and $4 \mu \mathrm{g} / \mathrm{ml}$, respectively. Maximal aggregation, expressed as the percentage of maximal light transmission, was measured.

\section{Statistical methods}

Results are presented as the mean \pm SEM. Statistical significance was set at $P<0.05$. Multivariate ANOVA with repeated measurements and correlation coefficients (exploratory factor analysis) were used. Dbase Stats (TM) by Ashton Tate and Statview SE + Graphics by Abacus were used for statistical analyses.

\section{Results}

Significant increases of noradrenaline plus decreases of adrenaline and dopamine plasma levels were registered at all post-amantadine periods. Maximal effects for these catecholamines occurred at 90 and $120 \mathrm{~min}$ periods (Fig. 1). Hence, significant increases in noradrenaline/ adrenaline and noradrenaline/dopamine ratios were also registered at these periods (Fig. 2).

Both f5-HT and p5-HT parameters showed significant decreases throughout the amantadine but not the placebo test. Tryptophan changes were not observed throughout the placebo or the amantadine tests (Fig. 3).

No significant increases of platelet aggregation were registered after the amantadine challenge (120 min).

Significant and sustained systolic blood pressure and heart rate decreases were registered throughout the 

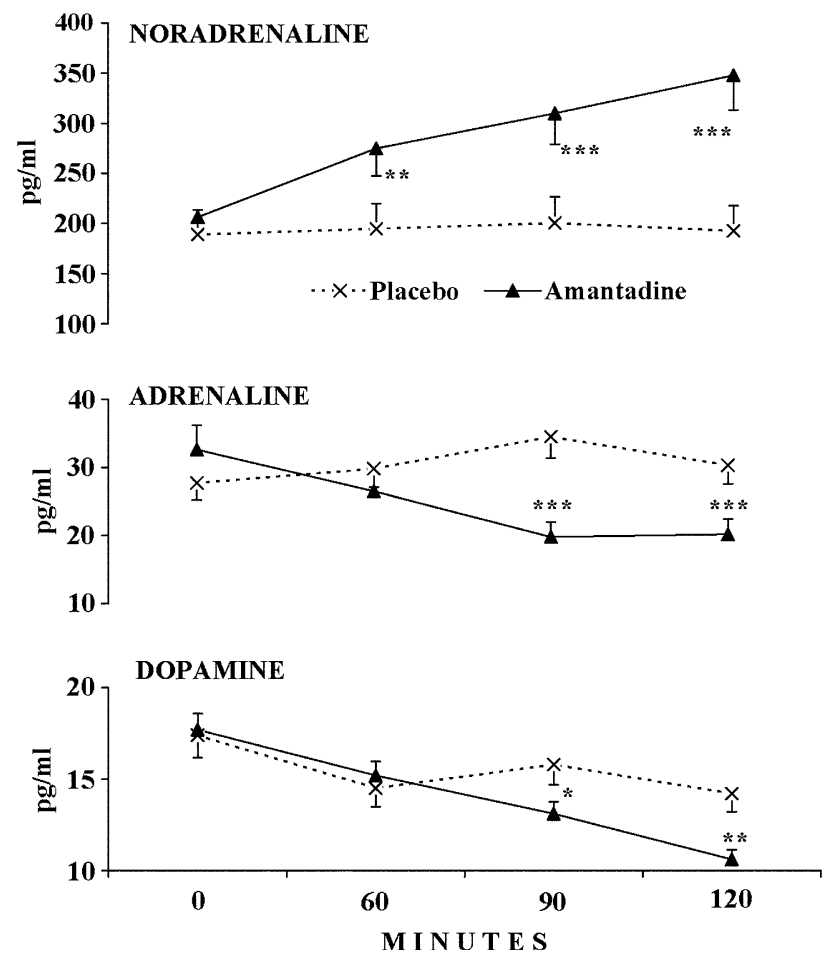

Fig. 1 Noradrenaline, adrenaline and dopamine plasma levels before and after placebo and amantadine test performed 2 weeks apart in 35 healthy volunteers (19 men and 16 women). Results are expressed as mean $+\mathrm{SE}$ as the error bars. $* P<0.05$, ${ }^{*} P P<0.01, * * * P<0.001$ (amantadine versus placebo)

amantadine but not the placebo test. Conversely, significant and sustained diastolic blood pressure rises were observed after the amantadine challenge but not after the placebo administration (Fig. 4). Hence, amantadine minimized systolic blood pressure plus heart rate and enhanced diastolic blood pressure.

Significant and progressive negative correlations were found between NA and DA and between NA/Ad ratio and DA throughout the amantadine test. Positive correlations were found between NA/Ad ratio and diastolic blood pressure. Adrenaline versus f5-HT showed significant positive correlation values at post-drug periods (see Table 1).

\section{Discussion}

We demonstrated in the present study that a small dose of oral amantadine triggered abrupt and significant reduction of the adrenaline plasma levels which contrasted the significant rises of plasma noradrenaline. In addition, significant reductions of dopamine plasma values were also registered. Furthermore, maximal decreases of both p5-HT and f5-HT were produced throughout the test.
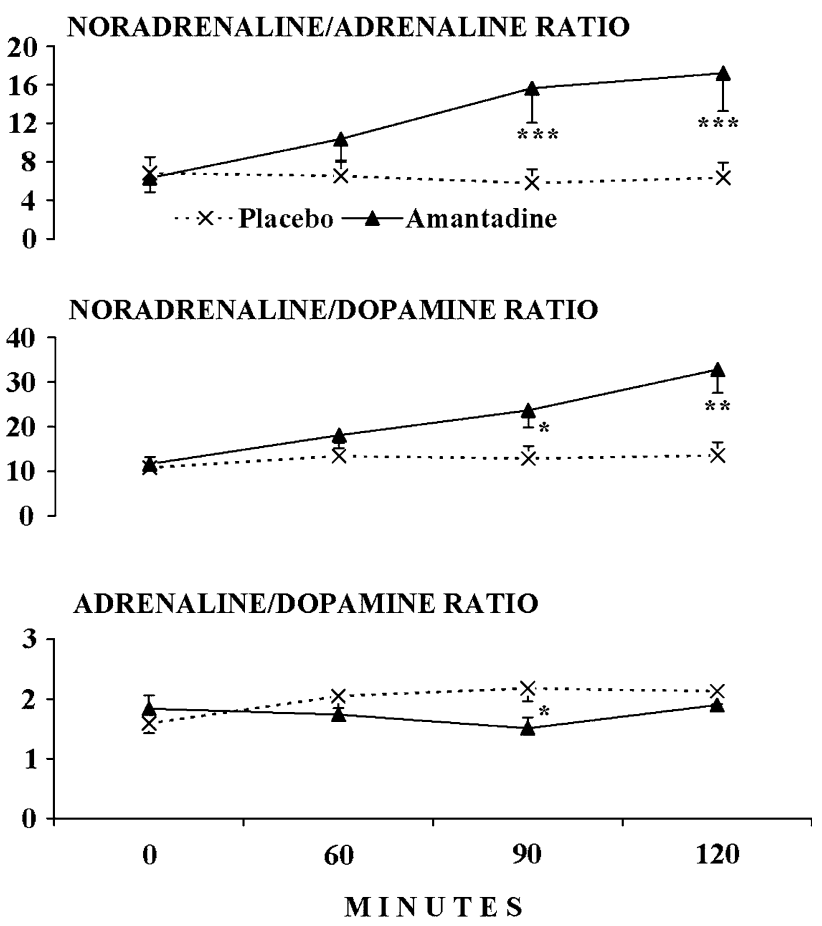

Fig. 2 Amantadine induced a significant rises of the noradrenaline/ adrenaline ratio as well as on the noradrenaline/dopamine ratio at the 90 and 120 min periods while a light significant fall was registered at 90 min period on the adrenaline/dopamine ratio after placebo and amantadine tests were performed 2 weeks apart in 35 healthy volunteers (19 men and 16 women). Results are expressed as mean $+\mathrm{SE}$ as the error bars. $* P<0.05,{ }^{*} P<0.01$, $* * * P<0.001$ (amantadine versus placebo)

The enhancement of both the NA/AD plus NA/DA ratios registered after the amantadine challenge is consistent with the postulation of the minimization of the adrenal sympathetic activity plus the enhancement of the neural sympathetic activity. With respect to this, it should be remembered that the A5(NA) pontomedullary nucleus, which interchanges inhibitory axons with the C1(Ad) RVL medullary nuclei (Byrum and Guyenet 1987; Guyenet 1984; Morrison et al. 1991), is responsible for the neural sympathetic activity (Morrison et al. 1991; Woodruff et al. 1986), whereas the latter nuclei excite adrenal glands secretion of catecholamines (Ad + DA and NA) (Strack et al. 1989). These medullary nuclei are crowded by excitatory glutamatergic (NMDA) receptors (Caringi et al. 1998; Drye et al. 1990; Elenkov et al., 2000; Li et al. 1992; Loewy and Haxhiu 1993; Maiorov et al. 1999; Strack et al. 1989).

The significant and abrupt fall of serotonin plasma levels (f5-HT) registered in this study should be attributed to the minimization of circulating adrenaline, triggered by the drug. Thus, 5-HT is retained into the platelet store. This issue is consistent with the significant positive correlations between adrenaline versus f5-HT values, registered throughout the post-amantadine periods. This factor should 

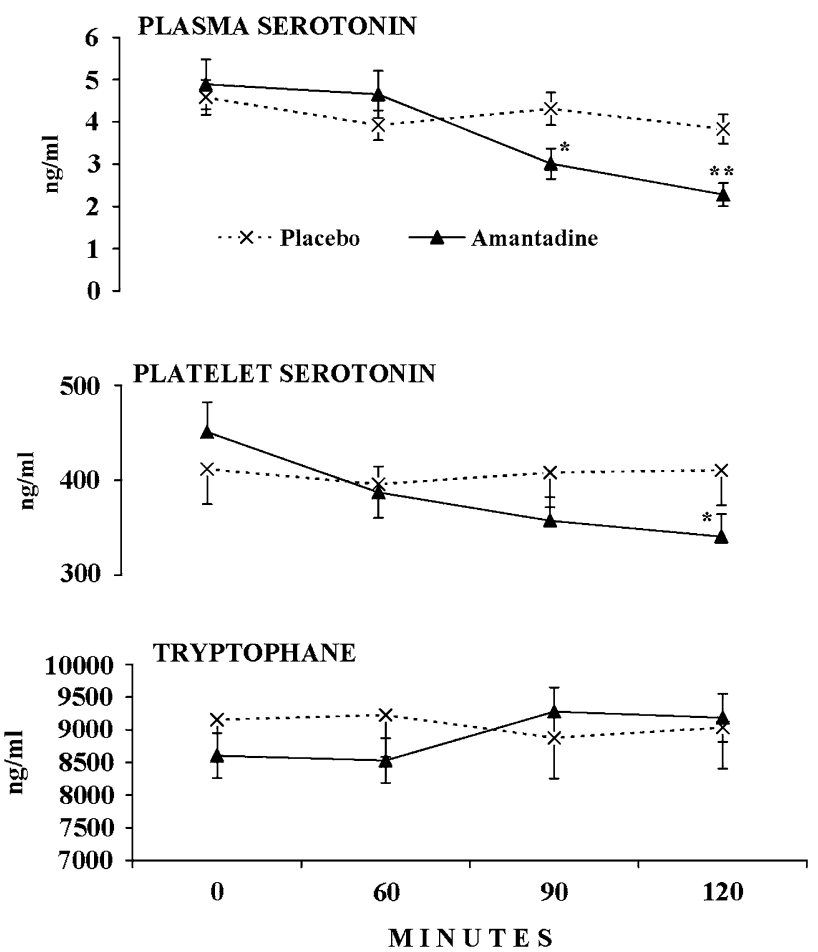

Fig. 3 Plasma serotonin, platelet serotonin and plasma tryptophan circulating levels before and after placebo and amantadine test performed 2 weeks apart in 35 healthy volunteers (19 men and 16 women). Results are expressed as mean $+\mathrm{SE}$ as the error bars. $* P<0.05,{ }^{*} P<0.01, * * * P<0.001$ (amantadine versus placebo)

be added to the reduction of parasympathetic activity triggered by the overwhelming neural sympathetic predominance registered after the amantadine challenge. With respect to this, it should be known that parasympathetic nerves excite enterochromaffin cells which release serotonin to the blood stream (Schwörer et al. 1987; Tobe et al. 1976). In addition, circulating acetylcholine interferes with the uptake of 5-HT by platelets (Rausch et al. 1985). Furthermore, plasma serotonin excites the medullary area postrema (it is located outside of the blood brain barrier) (Reynolds et al. 1989; Wilson and Bonham 1994). This nucleus sends excitatory axons to the $\mathrm{C} 1(\mathrm{Ad})$ nuclei (Gauthier and Reader 1982; Urbanski and Sapru 1988), thus minimization of this mechanism is responsible for the inhibition of the adrenal sympathetic activity, normally registered during postprandial periods (Lechin 2000; Lechin et al. 1993; 2009). Hence, amantadine would also be able to annul adrenal sympathetic activity throughout the minimization of the area postrema- $\mathrm{C} 1(\mathrm{Ad})$ axis which depends on the serotonin release by enterochromaffin cells during postprandial parasympathetic period. With respect to the latter, it has been demonstrated that the $\mathrm{C} 1(\mathrm{Ad})$ nuclei receive excitatory axons from the area postrema (Schwörer et al. 1987; Tobe et al. 1976; Urbanski and Sapru 1988).
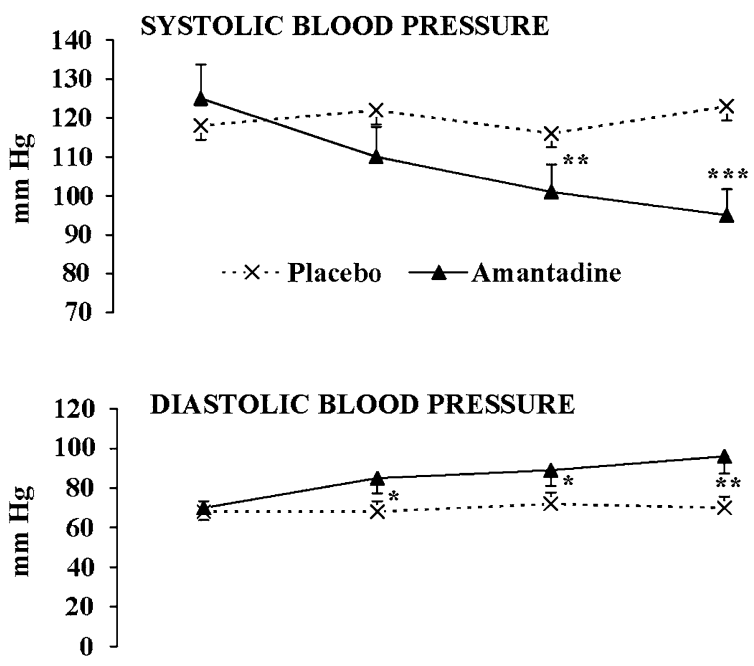

HEART RATE

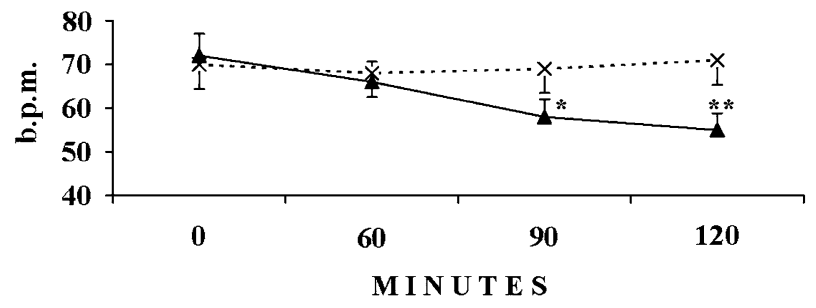

Fig. 4 Cardiovascular parameters registered before and after placebo and amantadine test performed 2 weeks apart in 35 healthy volunteers (19 men and 16 women). Results are expressed as mean $+\mathrm{SE}$ as the error bars. $* P<0.05$, $* * P<0.01$, $* * * P<0.001$ (amantadine versus placebo)

Table 1 Significant correlations $(r)$ after oral administration of amantadine $100 \mathrm{mg}$ or placebo in 35 healthy volunteers (19 men and 16 women

\begin{tabular}{llll}
\hline & $60 \mathrm{~min}$ & $90 \mathrm{~min}$ & $120 \mathrm{~min}$ \\
\hline NA versus DA & & & \\
$\begin{array}{l}\text { Amantadine } \\
\text { Placebo }\end{array}$ & $-0.43^{* *}$ & $-0.67^{* * *}$ & $-0.81^{* * *}$ \\
$\begin{array}{l}\text { NA/Ad versus DA } \\
\text { Amantadine }\end{array}$ & $-0.61^{* *}$ & n.s. & n.s. \\
$\begin{array}{l}\text { Placebo } \\
\text { NA/Ad versus DBP }\end{array}$ & n.s. & n.s. & n.s. \\
$\begin{array}{l}\text { Amantadine } \\
\text { Placebo }\end{array}$ & $0.54^{*}$ & $0.65^{* * *}$ & $0.69^{* * *}$ \\
Ad versus f5-HT & n.s. & n.s. & n.s. \\
Amantadine & $0.58^{* *}$ & $0.69^{* *}$ & $0.77^{* * *}$ \\
Placebo & n.s & n.s & n.s \\
\hline
\end{tabular}

NA noradrenaline, $D A$ dopamine, $A d$ adrenaline, $D B P$ diastolic blood pressure, n.s. non-significant

$* P<0.05, * * P<0.01, * * * P<0.001$ 
Summarizing, it should be concluded that amantadine annulled both parasympathetic and adrenal sympathetic activities and favored neural sympathetic predominance. In addition, the neural sympathetic overactivity provoked by amantadine interferes with the parasympathetic drive responsible for the release of intestinal serotonin which redounded in the reduction of both p5-HT and f5-HT circulating levels. With respect to this, we have quoted exhaustive evidence showing the existence of two types of opposite ANS profiles which underlie most diseases: (1) adrenal sympathetic and (2) neural sympathetic (Lechin and van der Dijs 2008, 2009a, b).

According to all the above, we concluded that the administration of an oral dose of amantadine was able to provoke the enhancement of the neural sympathetic branch which minimized both adrenal sympathetic and parasympathetic activities, as reflected by the peripheral autonomic system parameters plus the circulating neurotransmitters profile. The above findings allow the understanding of several therapeutic effects triggered by this drug.

Open Access This article is distributed under the terms of the Creative Commons Attribution Noncommercial License which permits any noncommercial use, distribution, and reproduction in any medium, provided the original author(s) and source are credited.

\section{References}

Bazil MK, Gordon FJ (1993) Sympathoexcitation from the rostral ventrolateral medulla is mediated by spinal NMDA receptors. Brain Res Bull 31(3-4):273-278

Bibbiani F, Oh JD, Kielaite A, Collins MA, Smith C, Chase TN (2005) Combined blockade of AMPA and NMDA glutamate receptors reduces levodopa-induced motor complications in animal models of PD. Exp Neurol 196(2):422-429

Born GVR (1962) Aggregation of blood platelets by adenosine diphosphate and its reversal. Nature 194:927-929

Byrum CE, Guyenet PG (1987) Afferent and efferent connections of the A5 noradrenergic cell group in the rat. J Comp Neurol 261(4):529-542

Caringi D, Maher TJ, Chaiyakul P, Asmundsson G, Ishide T, Ally A (1998) Extracellular glutamate increases in rostral ventrolateral medulla during static muscle contraction. Pflugers Arch 435(4):465-471

Drye RG, Baisden RH, Whittington DL, Woodruff ML (1990) The effects of stimulation of the A5 region on blood pressure and heart rate in rabbits. Brain Res Bull 24(1):33-39

Elenkov IJ, Wilder RL, Chrousos GP, Vizi ES (2000) The sympathetic nerve - an integrative interface between two supersystems: the brain and the immune system. Pharmacol Rev 52(4):595-638

Gauthier P, Reader TA (1982) Adrenomedullary secretory response to midbrain stimulation in rat: effects of depletion of brain catecholamines or serotonin. Can J Physiol Pharmacol 60(12): 1464-1474

Guyenet PG (1984) Baroreceptor-mediated inhibition of A5 noradrenergic neurons. Brain Res 303(1):31-40

Hand GA, Potts JT, Treuhaft BS, Wilson LB, Petty F, Mitchell JH (1997) Static muscle contraction elicits a baroreflex-dependent increase in glutamate concentration in the ventrolateral medulla. Brain Res 748(1-2):211-218

Lechin F (2000) Central and plasma 5-HT, vagal tone and airways. Trends Pharmacol Sci 21:425

Lechin F, van der Dijs B (2006a) Central nervous system circuitry and peripheral neural sympathetic activity responsible for essential hypertension. Review. Curr Neurovasc Res 3(4):307-325

Lechin F, van der Dijs B (2006b) Central nervous system (CNS) circuitry involved in the hyperinsulinism syndrome. Neuroendocrinology 84:222-234

Lechin F, van der Dijs B (2008) Central nervous system circuitries underlying two types of peripheral autonomic nervous system disorders. Open Neurosci J 2:41-50

Lechin F, van der Dijs B (2009a) Central nervous system plus autonomic nervous system disorders responsible for the gastrointestinal and pancreatobiliary diseases. Review. Dig Dis Sci 54:458-470. doi:10.1007/s10620-008-0369-9

Lechin F, van der Dijs B (2009b) Crosstalk between the autonomic nervous system and the central nervous system: mechanistic and therapeutic considerations for neuronal, immune, vascular, and somatic based diseases. In: Maiese K (ed) Neurovascular medicine: pursuing cellular longevity for healthy aging. Oxford University Press, New York, pp 101-152

Lechin F, van der Dijs B, Lechin M, Jara H, Lechin A, Lechin-Báez S, Orozco B, Rada I, Cabrera A, Arocha L, Jiménez V, León G (1993) Plasma neurotransmitters throughout an oral glucose tolerance test in essential hypertension. Clin Exp Hypertens 15:209-240

Lechin F, van der Dijs B, Benaim M (1996) Stress versus depression. Review. Prog Neuropsychopharmacol Biol Psychiatry 20:899_ 950

Lechin F, van der Dijs B, Jara H, Orozco B, Baez S, Benaim M, Lechin M, Lechin A (1998) Effects of buspirone on plasma neurotransmitters in healthy subjects. J Neural Transm 105(6/ 7):561-573

Lechin F, van der Dijs B, Pardey-Maldonado B, Rivera JE, Lechin ME, Baez S (2009) Amantadine reduces glucagon and enhances insulin secretion throughout the oral glucose tolerance test: central plus peripheral nervous system mechanisms. Diabetes Metab Syndr Obes 2:203-213

Li YW, Wesselingh SL, Blessing WW (1992) Projections from rabbit caudal medulla to $\mathrm{C} 1$ and $\mathrm{A} 5$ sympathetic premotor neurons, demonstrated with phaseolus leucoagglutinin and herpes simplex virus. J Comp Neurol 317:379-395

Loewy AD, Haxhiu MA (1993) CNS cell groups projecting to pancreatic parasympathetic preganglionic neurons. Brain Res 620:323-330

Maiorov DN, Wilton ER, Badoer E, Petrie D, Head GA, Malpas SC (1999) Sympathetic response to stimulation of the pontine A5 region in conscious rabbits. Brain Res 815(2):227-236

Morrison SF, Callaway J, Milner TA, Reis DJ (1991) Rostral ventrolateral medulla: a source of the glutamatergic innervation of the sympathetic intermediolateral nucleus. Brain Res 562(1):126-135

Rausch JL, Janowsky DS, Risch SC, Huey LY (1985) Physostigmine effects on serotonin uptake in human blood platelets. Eur J Pharmacol 109:91-96

Reynolds DJM, Leslie RA, Grahame-Smith DG, Harvey JM (1989) Localization of $5-\mathrm{HT}_{3}$ receptor binding sites in human dorsal vagal complex. Eur J Pharmacol 174:127-130

Schwörer H, Racké K, Kilbinger H (1987) Cholinergic modulation of the release of 5-hydroxytryptamine from the guinea pig ileum. Naunyn Schmiedebergs Arch Pharmacol 336(2):127-132

Strack AM, Sawyer WB, Platt KB, Loewy AD (1989) CNS cell groups regulating the sympathetic outflow to adrenal gland as 
revealed by transneuronal cell body labeling with pseudorabies virus. Brain Res 491(2):274-296

Tobe T, Izumikawa F, Sano M, Tanaka C (1976) Release mechanisms of 5-HT in mammalian gastrointestinal tract-especially vagal release of 5-HT. In: Fujita T (ed) Endocrine gut-pancreas. Elsevier, Amsterdam, pp 371-390

Urbanski RW, Sapru HN (1988) Evidence for a sympathoexcitatory pathway from the nucleus tractus solitarii to the ventrolateral medullary pressor area. J Auton Nerv Syst 23(2):161-174
Wilson CG, Bonham AC (1994) Area postrema excites and inhibits sympathetic-related neurons in rostral ventrolateral medulla in rabbit. Am J Physiol 266(3 Pt 2):H1075-H1086

Woodruff ML, Baisden RH, Whittington DL (1986) Effects of electrical stimulation of the pontine A5 cell group on blood pressure and heart rate in the rabbit. Brain Res 379(1):10-23

Young JB, Rosa RM, Landsberg L (1984) Dissociation of sympathetic nervous system and adrenal medullary responses. Am J Physiol 247(1 Pt 1):E35-E40 